\title{
Fitness, Fatness and Active School Commuting among Liverpool Schoolchildren
}

\author{
Robert J. Noonan ${ }^{1,2, *}$ (D), Lynne M. Boddy ${ }^{2}$, Zoe R. Knowles ${ }^{2}$ and Stuart J. Fairclough ${ }^{1,3}$ \\ 1 Department of Sport and Physical Activity, Edge Hill University, Ormskirk L39 4QP, UK; \\ Stuart.Fairclough@edgehill.ac.uk \\ 2 Physical Activity Exchange, Research Institute for Sport and Exercise Sciences, Liverpool John \\ Moores University, Liverpool L3 2AB, UK; Lynne.M.Boddy@ljmu.ac.uk (L.M.B.); \\ Zoe.R.Knowles@ljmu.ac.uk (Z.R.K.) \\ 3 Department of Physical Education and Sport Sciences, University of Limerick, Limerick V94 T9PX, Ireland \\ * Correspondence: Robert.Noonan@edgehill.ac.uk; Tel.: +44-1695-584-488
}

Received: 1 August 2017; Accepted: 30 August 2017; Published: 31 August 2017

\begin{abstract}
This study investigated differences in health outcomes between active and passive school commuters, and examined associations between parent perceptions of the neighborhood environment and active school commuting (ASC). One hundred-ninety-four children (107 girls), aged 9-10 years from ten primary schools in Liverpool, England, participated in this cross-sectional study. Measures of stature, body mass, waist circumference and cardiorespiratory fitness (CRF) were taken. School commute mode (active/passive) was self-reported and parents completed the neighborhood environment walkability scale for youth. Fifty-three percent of children commuted to school actively. Schoolchildren who lived in more deprived neighborhoods perceived by parents as being highly connected, unaesthetic and having mixed land-use were more likely to commute to school actively $(p<0.05)$. These children were at greatest risk of being obese and aerobically unfit $(p<0.01)$. Our results suggest that deprivation may explain the counterintuitive relationship between obesity, CRF and ASC in Liverpool schoolchildren. These findings encourage researchers and policy makers to be equally mindful of the social determinants of health when advocating behavioral and environmental health interventions. Further research exploring contextual factors to ASC, and examining the concurrent effect of ASC and diet on weight status by deprivation is needed.
\end{abstract}

Keywords: child; active commuting; physical activity; fitness; weight; obesity; neighborhood; deprivation; poverty; obesogenic

\section{Introduction}

Childhood obesity and poor health are most prevalent in areas of high deprivation [1-3]. Physical activity (PA) improves child health, including weight status [4,5] and cardiorespiratory fitness (CRF) [6]. Active school commuting (ASC) is recognized as an important component of PA and is associated with higher daily PA [7,8]. In England, ASC prevalence among schoolchildren has progressively declined since 1995 [9], but remains consistently highest among schoolchildren from deprived backgrounds [10-12].

In recent years, there has been an increasing focus by the UK government to promote and increase ASC among schoolchildren with a view to curbing rising obesity levels [13]. However, evidence to support the positive contribution of ASC to children's weight status is inconsistent $[14,15]$. For example, Voss and Sandercock [16] found no association between ASC and weight status whereas other studies have reported a weak inverse $[17,18]$ and positive association [19]. The effect of ASC on other components of physical health such as CRF are also inconsistent $[20,21]$. Studies that have reported a positive association have been conducted outside of the UK in countries that experience 
greater cycling prevalence during ASC. Cycling is a stronger predictor of CRF in comparison to walking which is the most common form of ASC among UK children [16,22,23]. Therefore, further research is needed to explore the contribution of ASC to UK schoolchildren's health.

ASC is influenced by multiple environmental factors. Household distance to school is considered the strongest influence with shorter distances associated with higher levels of ASC [24-26]. However, parents' assessment of environmental attributes related to safety are also known to play an important role in determining whether children commute actively to school $[27,28]$. Neighborhoods perceived by parents as having well-connected streets, good land-use mix and residential density have been linked with higher ASC $[29,30]$. However, these reported associations are based on data from the USA [27,30] and Australia [31], which limits generalization to UK children. To promote and support ASC among UK schoolchildren, it is important to understand which environmental attributes support and restrict ASC. The Neighborhood Environment Walkability Scale-Youth (NEWS-Y), developed by Rosenberg et al. [32] provides an empirically derived measure of various built environmental attributes that may influence ASC. The NEWS-Y has been used to investigate associations between parental perceptions of the neighborhood environment and child PA [33,34] but not ASC. Therefore, the aims of this study were to (1) investigate differences in health outcomes between active and passive school commuters; and (2) examine associations between parent perceptions of the neighborhood environment and ASC.

\section{Materials and Methods}

\subsection{Participants}

Study participants were 9-10 years-old schoolchildren recruited from ten primary schools in Liverpool, England. Liverpool is ranked the most deprived English city [35] and obesity rates among children aged $10-11$ years exceed the national average (23.0\% vs. $18.9 \%$; [36]). All eligible participants $(n=326)$ in participating schools received a participant recruitment pack containing parent and child information sheets, consent and assent forms, and a medical screening form. Written informed consent and assent were received from parents and their children, respectively, before children could participate in the study. Completed informed parental consent and child assent were obtained for 217 children (39.5\% response rate). Liverpool John Moores University Ethics Committee approved the study (13/SPS/048) and data collection took place between January and April 2014.

\subsection{Measures}

\subsubsection{Anthropometrics}

Stature and sitting stature were measured to the nearest $0.1 \mathrm{~cm}$ using a portable stadiometer (Leicester Height Measure, Seca, Birmingham, UK). Leg length was calculated by subtracting sitting stature from stature. Body mass was measured to the nearest $0.1 \mathrm{~kg}$ using calibrated scales (Seca, Birmingham, UK). Body mass index (BMI) was calculated from stature and body mass as a proxy measure of body composition $\left(\mathrm{kg} / \mathrm{m}^{2}\right)$ and BMI z-scores were assigned to each child [37]. Age and sex-specific BMI cut-points were used to classify children as normal weight or overweight/obese [38]. Waist circumference was measured at the midpoint between the bottom rib and the iliac crest to the nearest $0.1 \mathrm{~cm}$ using a non-elastic measuring tape (Seca, Birmingham, UK). Gender-specific regression equations were used to predict children's age from peak height velocity (APHV; [39]). This calculation was used as a proxy measure of biological maturation.

\subsubsection{Cardiorespiratory Fitness}

CRF was assessed using the Sports Coach UK 20 m multistage shuttle run test (20mSRT; [40]. Children completed $20 \mathrm{~m}$ shuttle runs keeping in time with an audible 'bleep' signal. The time between bleeps progressively decreases, increasing the intensity of the test. Children were encouraged to run to 
exhaustion, and the number of completed shuttles was recorded for each participant and retained for analysis. Age and sex specific cut-points were used to classify children as 'fit' or 'unfit' [41].

\subsubsection{School Commute Data}

School commute mode was child-reported. Responses included (walk, cycle, scooter, bus, car, train, taxi, other). Responses were dichotomized into (0 reference category) active transport and (1) passive transport. Household distance to school was objectively measured using Google maps online route planner (https://www.google.co.uk/maps). The shortest route from school addresses to parent-reported home addresses was used [42].

\subsubsection{Neighborhood Environment}

Parental perceptions of neighborhood attributes were assessed using the Neighborhood Environment Walkability Scale for Youth (NEWS-Y). The NEWS-Y is a 67-item scale, organized into nine subscales representing land-use mix diversity, neighborhood recreation facilities, residential density, land-use mix-access, street connectivity, walking/cycling facilities, neighborhood aesthetics, pedestrian and road traffic safety, and crime safety. The NEWS-Y has demonstrated acceptable to good test-retest reliability (ICC $=0.56-0.87$; [32]) and has been used previously in child PA research [33,34]. Items are averaged and higher scores denote higher walkability. Higher neighborhood scores indicate a more walkable environment for all items except pedestrian and road traffic safety, and crime safety items, where higher scores indicate lower walkability [32]. An overall NEWS-Y score was calculated from the sum of $z$-scores for each of the nine subscales.

\subsubsection{Deprivation}

Area level deprivation was calculated using the 2015 indices of multiple deprivation (IMD; [35]). The IMD is a UK government-produced measure comprising seven areas of deprivation (income, employment, health, education, housing, environment, and crime). Parent reported home postcodes were imported into the GeoConvert application [43] to generate deprivation scores. Higher deprivation was represented by lower deprivation scores. Sixty-eight percent of the study sample were above the IMD cut-off value (26.83) for the most nationally deprived tertile for England. We calculated a 50th centile IMD score of 35.63 for the sample, and created one IMD median-split categorical variable to provide two groups representative of children living in areas of high-deprivation (HD; median IMD score 49.76) and high-to-medium deprivation (MD; median IMD score 22.86; [34]).

\subsection{Analysis}

Participant characteristics were analyzed descriptively. Independent sample $t$-tests and $\chi^{2}$ compared descriptive data between genders. For study aim 1, multivariate analysis of covariance (MANCOVA) assessed differences in health outcomes by school commute mode (active vs passive) adjusted for gender, APHV, and school commute distance. $\chi^{2}$ with odds ratios (OR) as a measure of effect examined school commute mode group differences in weight status, aerobic fitness, deprivation and school commute distance. The same analyses were repeated to examine deprivation group differences in weight status, aerobic fitness, school commute mode and school commute distance. For study aim 2, multivariate logistic regression analyses assessed associations between parent perceptions of the neighborhood environment and ASC controlling for school commute distance and IMD. Statistical significance was set to $p \leq 0.05$. All analyses were conducted using IBM SPSS Statistics version 23 (IBM, Armonk, NY, USA).

\section{Results}

Of the 217 children who returned written parental informed consent and participant assent, six participants were not present on the day of testing, and a further 17 children had incomplete data. 
Thus, data were available from 194 children (107 girls) (35.3\% response rate). Participant characteristics are presented in Table 1. Preliminary analyses revealed no significant differences between included and excluded participants. Boys were taller $(p<0.05)$ and aerobically fitter than girls $(p<0.01)$ who were closer to maturation than boys $(p<0.001)$. More children commuted to school actively $(52.6 \%)$ than passively $(47.4 \%)$. Walking was the most common mode of commuting to school (47.4\%), followed by car $(44.8 \%)$, cycle $(4.1 \%)$, bus $(2.1 \%)$, scooter $(1.0 \%)$, and other $(0.5 \%)$. Active school commuters had significantly higher BMI $(p=0.02)$, BMI $z$-score $(p=0.05)$ and waist circumference $(p=0.01)$ than passive school commuters (Table 2). Differences were also observed for CRF but these did not reach statistical significance $(p>0.05)$. Children that lived closer to school had higher BMI, BMI $z$-scores and waist circumference but these did not reach statistical significance $(p>0.05)$.

Table 1. Participant characteristics (mean $\pm \mathrm{SD}$ ).

\begin{tabular}{cccc}
\hline Variable & All $(\boldsymbol{n}=\mathbf{1 9 4})$ & Boys $(\boldsymbol{n}=\mathbf{8 7})$ & Girls $(\boldsymbol{n}=\mathbf{1 0 7})$ \\
\hline Age & $9.96(0.30)$ & $9.97(0.30)$ & $9.95(0.30)$ \\
Stature $(\mathrm{cm})$ & $139.12(7.30)$ & $140.42(6.99)$ & $138.06(7.41)^{*}$ \\
Mass $(\mathrm{kg})$ & $35.01(8.44)$ & $35.68(7.68)$ & $34.45(9.01)$ \\
BMI $\left(\mathrm{kg} / \mathrm{m}^{2}\right)$ & $17.92(3.20)$ & $17.96(2.90)$ & $17.89(3.43)$ \\
\hline Weight status $(\%)$ & & \\
\hline Normal weight & 75.30 & 79.30 & 72.00 \\
Overweight/obese & 24.70 & 20.60 & 28.00 \\
BMI z-score & $0.32(1.25)$ & $0.51(1.16)$ & $0.16(1.30)$ \\
Waist circumference & $63.84(7.72)$ & $64.57(7.97)$ & $63.24(7.50)$ \\
APHV & $-2.64(0.93)$ & $-3.49(0.45)$ & $-1.94(0.57))^{* * *}$ \\
CRF (shuttles) & $38.18(19.37)$ & $48.37(20.05)$ & $29.90(14.22){ }^{* * *}$ \\
Aerobically fit $(\%)$ & 67.00 & 77.00 & $58.90 * *$ \\
Commute distance $(\mathrm{km})$ & $1.68(1.77)$ & $1.60(1.53)$ & $1.74(1.95)$ \\
\hline School commute mode $(\%)$ & & & 52.30 \\
\hline Active & 52.60 & 52.90 & 47.70 \\
Passive & 47.40 & 47.10 & $0.02(3.15)$ \\
IMD score & $36.80(18.20)$ & $36.87(19.62)$ & $36.73(17.05)$ \\
NEWS-Y & $0.03(3.16)$ & $0.05(3.19)$ &
\end{tabular}

APHV: age from peak height velocity; BMI: body mass index; CRF: cardiorespiratory fitness; NEWS-Y: neighborhood environment walkability scale-youth; IMD: indices of multiple deprivation. Significant gender difference at * $p<0.05$; ** $p<0.01 ;{ }^{* * *} p<0.001$.

Table 2. MANCOVA analyses of health-related variables by school commute mode group, adjusted for gender, APHV and school commute distance.

\begin{tabular}{cccc}
\hline Variable & Active Mean $\mathbf{9 5} \% \mathbf{C I})(\boldsymbol{n = 1 0 2 )}$ & Passive Mean $\mathbf{( 9 5 \% ~ C I ) ~}(\boldsymbol{n = 9 2 )}$ & $p$ Value \\
\hline BMI & $18.33(17.79-18.87)$ & $17.32(16.75-17.89)$ & 0.02 \\
BMI z-score & $0.45(0.23-0.67)$ & $0.12(-0.11-0.36)$ & 0.05 \\
Waist circumference & $64.84(63.57-66.11)$ & $62.29(60.95-63.64)$ & 0.01 \\
CRF & $37.98(34.37-41.60)$ & $38.99(35.16-42.84)$ & 0.72 \\
\hline
\end{tabular}

MANCOVA: multivariate analysis of covariance; BMI: body mass index; CI: confidence interval; CRF: cardiorespiratory fitness.

Table 3 presents OR for deprivation, CRF, and weight status by school commute mode. Children who used passive transport were more likely to be classified as healthy weight ( $\mathrm{OR}=2.17$, $95 \% \mathrm{CI}=1.10-4.30)$, aerobically fit ( $\mathrm{OR}=2.23,95 \% \mathrm{CI}=1.20-4.14)$, and live further away from school $(>0.5 \mathrm{~km}, \mathrm{OR}=38.14,95 \% \mathrm{CI}=5.08-286.62 ;>1.0 \mathrm{~km}, \mathrm{OR}=11.61,95 \% \mathrm{CI}=5.83-23.10)$, compared with children who commuted actively. 
Table 3. OR ( $95 \%$ CI) for likelihood of being classified as healthy weight, aerobically fit, and living within $1 \mathrm{~km}$ from school by school commute mode.

\begin{tabular}{ccccc}
\hline Variable & Active Mean (95\% CI) & $(\boldsymbol{n}=\mathbf{1 0 2})$ & Passive Mean (95\% CI) $(\boldsymbol{n}=\mathbf{9 2})$ & $p$ Value \\
\hline Healthy weight & $47.9 \%$ & $2.17(1.10-4.30)$ & $52.1 \%$ & 0.02 \\
\hline Aerobically fit & $46.2 \%$ & $2.23(1.20-4.14)$ & $53.8 \%$ & 0.01 \\
\hline Commute distance & & & \\
\hline$<0.5 \mathrm{~km}$ & $30.0 \%$ & $38.14(5.08-286.62)$ & $1.1 \%$ \\
\hline$<1.0 \mathrm{~km}$ & $73 \%$ & $11.61(5.83-23.10)$ & $<0.001$ \\
\hline
\end{tabular}

OR: Odds ratio.

Table 4 presents OR for school commute mode, CRF, weight status and distance from school by deprivation group. Compared with children who lived in areas of HD, MD children were more likely to commute to school passively ( $\mathrm{OR}=2.41,95 \% \mathrm{CI}=1.35-4.30)$, live further away from school $(<0.5 \mathrm{~km}$, $\mathrm{OR}=2.95,95 \% \mathrm{CI}=1.28-6.82 ;<1.0 \mathrm{~km}, \mathrm{OR}=2.06,95 \% \mathrm{CI}=1.16-3.68)$, be classified as healthy weight $(\mathrm{OR}=2.74,95 \% \mathrm{CI}=1.37-5.48)$, and aerobically fit $(\mathrm{OR}=2.52,95 \% \mathrm{CI}=1.35-4.70)$.

Table 4. OR (95\% CI) for likelihood of being classified as healthy weight, aerobically fit, an active commuter and living with $1 \mathrm{~km}$ from school by deprivation group.

\begin{tabular}{ccccc}
\hline Variable & MD Mean (95\% CI) or \% $(n=96)$ & HD Mean (95\% CI) or \% $(n=98)$ & $p$ Value \\
\hline Healthy weight & $84.4 \%$ & $2.74(1.37-5.48)$ & $<6.3 \%$ & $<0.01$ \\
\hline Aerobically fit & $77.1 \%$ & $2.52(1.35-4.70)$ & $57.1 \%$ & $<0.01$ \\
\hline Commute distance & & & 0.01 \\
\hline$<0.5 \mathrm{~km}$ & $9.4 \%$ & $2.95(1.28-6.82)$ & $23.4 \%$ & 0.01 \\
\hline$<1.0 \mathrm{~km}$ & $38.5 \%$ & $2.06(1.16-3.68)$ & $56.4 \%$ & $<0.01$ \\
\hline
\end{tabular}

ASC was positively associated with street connectivity $(B=0.62, \mathrm{OR}=1.66,95 \% \mathrm{CI}=1.16-2.96)$ and land-use mix diversity $(\mathrm{B}=0.55, \mathrm{OR}=1.86,95 \% \mathrm{CI}=1.01-2.73)$, and was inversely associated with neighborhood aesthetics $(\mathrm{B}=-0.44, \mathrm{OR}=0.65,95 \% \mathrm{CI}=0.44-0.95$; Table 5).

Table 5. Associations between neighborhood environment attributes and ASC.

\begin{tabular}{ccccc}
\hline Variable & B & SE & OR (95\% CI) & $p$ Value \\
\hline Land-use mix diversity & 0.62 & 0.24 & $1.86(1.16-2.96)$ & 0.01 \\
Constant & -1.80 & 0.73 & 0.17 & 0.01 \\
\hline Street connectivity & 0.50 & 0.26 & $1.66(1.01-2.73)$ & 0.04 \\
Constant & -1.45 & 0.76 & 0.23 & 0.06 \\
\hline Neighborhood aesthetics & -0.44 & 0.19 & $0.65(0.44-0.95)$ & 0.02 \\
Constant & 1.13 & 0.51 & 3.09 & 0.03 \\
\hline
\end{tabular}

B: unstandardized $\beta$ coefficient; SE: standard error; OR: odds ratio; OR $=\exp (\beta)$. Adjusted for IMD and school commute distance. Only variables that showed a statistically significant association with ASC are presented. 


\section{Discussion}

This study examined the association between active school commuting (ASC), body mass index (BMI) and cardiorespiratory fitness (CRF) in Liverpool schoolchildren. Counter to what might be assumed, we found that ASC was associated with higher BMI and lower CRF. The most recent systematic review in this area found that only $35.9 \%$ of included studies observed more favorable weight status among active school commuters relative to passive school commuters [14]. Fewer studies have reported an inverse relationship between ASC and child weight status $[17,18]$. There are several potential reasons for the inverse relationship found in this study.

Firstly, as observed here, children that commute to school actively tend to be from deprived backgrounds $[17,44,45]$, and deprived children are more likely to live in an obesogenic environment that encourages the consumption of unhealthy food and/or discourages physical activity, placing them at greater risk of obesity compared to affluent children [46-49]. The indices of multiple deprivation (IMD) captures a range of deprivation markers including the neighborhood environment [35]. In Liverpool, high-deprivation (HD) neighborhoods could be considered obesogenic, as they are less walkable and have less access to self-contained gardens/yards compared to high-to-medium deprivation (MD) neighborhoods [34]. Moreover, HD children are more likely to experience an unbalanced diet at home [50], and be exposed to fast food and takeaway outlets along the home-school commute route $[51,52]$, both of which are strong predictors of fatness [53,54]. To improve child health and foster more equitable neighborhoods requires an appreciation of the social determinants of health, and a structural approach to health promotion, through modifications to the physical, social, political, and economic environment in which children and families make health-related decisions $[55,56]$. Such changes may include but are not limited to improved infrastructure (e.g., sidewalks, bike lanes, and green spaces) and policy implementations (i.e., restrictions on fast food outlets and food marketing, and greater accessibility to affordable, healthy foods).

This study found an inverse association between ASC and CRF after deprivation was accounted for. Some previous studies have reported contrasting findings to those reported here $[15,21,57]$. However, these studies comprised a higher proportion of cyclists and observed higher CRF among cyclists compared to walkers and passive commuters $[15,57]$. In the present study, only $4.1 \%$ of children reported cycling to school. The average trip distance for cyclists is often greater than that of walkers and tends to be a more vigorous intensity activity [58]. It is well-established that high intensity PA ( $\geq 6$ METs) is necessary to improve children's CRF [59]. Walking is often performed at a moderate or light intensity, and thus, is unlikely to place the cardiorespiratory system under the necessary strain to confer positive adaptations to CRF. Presently, there is limited evidence for the association between walking to school and CRF among schoolchildren. Our findings add to the developing body of evidence.

Children that commuted actively to school lived closer to school than passive commuters. School to home commute distance is the strongest predictor of ASC [24,25]. D'Haese et al. [24] found that the criterion distance for walking to school in Belgium schoolchildren was $1.5 \mathrm{~km}$. Chillón and colleagues [60] found that a distance of $1.4 \mathrm{~km}$ best discriminated walkers from passive commuters in a UK study involving 10-year-old schoolchildren. School choice can significantly reduce opportunities for ASC and thus impact on strategies to promote ASC. Schoolchildren live further from school than ever before. Presently, less than half of all English schoolchildren attend their nearest school [9]. Current educational policies in the UK are counterintuitive to public health goals of increasing child PA, especially ASC, for example, permitting schools to enroll schoolchildren from wide catchment areas thus creating long commuting distances. In such contexts, efforts to promote widespread adoption of ASC may be unrealistic. The uptake and maintenance of ASC is likely to be dependent on government policies aligning with public health priorities, as well as community and societal level influences to create safe and feasible commuting routes.

This study found that after adjusting for area deprivation and distance to school, neighborhoods perceived by parents as having well-connected streets, mixed land-use, and unpleasant aesthetic 
features were associated with a higher likelihood of ASC. In contrast to previous research $[61,62]$, we observed an inverse association between neighborhood aesthetics and ASC. Our study is the first to investigate the association between ASC and parents' perceptions of various neighborhood attributes in UK schoolchildren. Previous studies were undertaken outside of the UK, did not adjust for distance to school [61], and were based on ASC among adolescent girls [62]. It is plausible to suggest that favorable neighborhood aesthetics (e.g., well maintained sidewalks, green spaces, low volumes of street litter and graffiti) may improve children's satisfaction of walking to school. However, many children in this study lived close to school and in neighborhoods classified as high deprivation. Whilst we cannot be certain that these children were from deprived backgrounds, deprivation is inversely associated with car access $[63,64]$, and thus may result in these children having no other option but to commute to school actively.

In agreement with previous research [65], we found that neighborhoods perceived by parents as having a well-connected street network with numerous intersections/crossings were positively associated with ASC. These neighborhood features result in shorter and more direct commute routes to school, which is a well-established predictor of ASC [24,26]. Moreover, routes to school that are more direct and well-connected and made up of minor rather than major roads are likely to be perceived by parents as safer and thus more conducive to ASC given that they experience less motorized traffic and are subject to lower speed limits $[29,66]$. The introduction of traffic calming measures within school catchment areas such as pedestrianization and street crossings would provide a more conducive environment for children's ASC and should be considered by future urban planners. Land-use mix diversity was also positively associated with ASC. A potential reason for this finding may be that neighborhoods with diverse land uses experience more people walking around the neighborhood and are thus more likely to be perceived by parents as safer [67]. Kerr et al. [61] and Larsen et al. [68] both found a positive relationship between land-use mix and ASC whereas Ewing et al. [69] reported contrasting findings. Further research is warranted to better understand how mixed land uses influences ASC.

Consistent with prior UK research, we found that children from highly deprived neighborhoods are most likely to commute to school actively [10-12]. One reason for this is that children from deprived neighborhoods are less likely to live in a family that owns a car $[63,64]$. Deprived children therefore commute to school actively in most part by necessity rather than choice. The distinction though between necessity and choice with regards to ASC is seldom explored in the literature. Of particular interest is the potential psychological strain placed on children and in the case of younger children, their parents, through relying on such forms of transport in often-unpleasant environments [70,71]. This could impact negatively on children's motivation to participate in PA, especially walking for leisure in both the short and long-term. Further qualitative research is warranted to explore children's perceptions of ASC, including the benefits and challenges they experience.

Importantly, it is not our intention to suggest that ASC is detrimental for Liverpool schoolchildren's health. Rather, Liverpool schoolchildren with poorer health because they are deprived are more likely to commute actively to school, for reasons that warrant further investigation. Rather than advocating for those that participate [deprived children] to actively commute more to improve their weight status, we suggest that the challenge remains to identify ways to reduce deprivation, and increase ASC prevalence among the nonparticipants, especially those that live in close proximity to school. A recent UK study [72] exploring the habitual PA behaviors of a nuclear and single parent family, found that the nuclear family used the family car for short commute distances including the home to school commute $(1.1 \mathrm{~km})$. Future studies should consider recruiting such passive commuters that reside close to home to understand their decision to not commuting actively.

This is the first study to explore the influence of neighborhood attributes on schoolchildren's ASC using the NEWS-Y survey. Several limitations are though, worthy of consideration. Our study used cross-sectional data, which limits inference of causality. When compared with the national average, children in this study lived in more deprived areas and had higher BMI. Therefore, generalizing our 
findings to more affluent and rural areas of the UK should be done with caution. The NEWS-Y survey is a valid and reliable measure of neighborhood attributes [32] but may be open to bias from respondents. The IMD is a well-established measure of deprivation reflecting a range of deprivation markers, but may not have accurately reflected the actual deprivation level of all participating schoolchildren. We did not assess sedentary time or energy intake, which both contribute to energy balance. Moreover, the relatively small sample size and low participant response rate may have biased results with active children more likely to have taken part in the study. Furthermore, we did not explore questions of context, which limits discussion on children's reasons for commuting actively or passively to school. Although commute distance was measured objectively, this may not accurately reflect actual commute distance taken for all children. Another limitation is the fact that some children can be driven to school in the morning but commute actively in the afternoon. However, we did not distinguish between active, passive or 'mixed transport' commuters. Despite these limitations, the findings reported here are consistent with larger-scale studies $[17,18]$.

\section{Conclusions}

In this study, schoolchildren who lived in more-deprived neighborhoods perceived by parents as being highly connected, unaesthetic and having mixed land-use were more likely to commute to school actively. These children were at greatest risk of being obese and aerobically unfit. Our findings suggest that deprivation may explain the counterintuitive relationship between obesity, cardiorespiratory fitness (CRF) and active school commuting (ASC) in Liverpool schoolchildren. These findings encourage researchers and policy makers to be mindful of the social determinants of health when planning and advocating behavioral and environmental health interventions. Further research exploring contextual factors to ASC, and examining the concurrent effects of ASC and diet on weight status by deprivation is needed. To improve child health and alleviate deprivation requires a systems approach to health promotion and actions on inequalities in wider social determinants operating outside the health system.

Acknowledgments: The authors would like to thank all of the children and parents who participated in the study. The research was funded by Liverpool John Moores University.

Author Contributions: Robert J. Noonan was responsible for the design of the study, data collection, analyses and drafted the manuscript; Lynne M. Boddy, Zoe R. Knowles and Stuart J. Fairclough contributed to the design of the study and editing the manuscript. All authors read and approved the final manuscript.

Conflicts of Interest: The authors declare no conflict of interest.

\section{References}

1. Marmot, M. Fair Society, Healthy Lives: The Marmot Review. Strategic Review of Health Inequalities in England Post 2010; Department for International Development: London, UK, 2010.

2. Wickham, S.; Anwar, E.; Barr, B.; Law, C.; Taylor-Robinson, D. Poverty and child health in the UK: Using evidence for action. Arch. Dis. Child. 2016, 101, 759-766. [CrossRef] [PubMed]

3. Wu, S.; Ding, Y.; Wu, F.; Li, R.; Hu, Y.; Hou, J.; Mao, P. Socio-economic position as an intervention against overweight and obesity in children: A systematic review and meta-analysis. Sci. Rep. 2015, 5, 11354. [CrossRef] [PubMed]

4. Guinhouya, B.C. Physical activity in the prevention of childhood obesity. Paediatr. Perinat. Epidemiol. 2012, 26, 438-447. [CrossRef] [PubMed]

5. Hills, A.P.; Andersen, L.B.; Byrne, N.M. Physical activity and obesity in children. Br. J. Sports Med. 2011, 45, 866-870. [CrossRef] [PubMed]

6. Boddy, L.M.; Murphy, M.H.; Cunningham, C.; Breslin, G.; Foweather, L.; Gobbi, R.; Graves, L.E.F.; Hopkins, N.D.; Auth, M.K.H.; Stratton, G. Physical Activity, Cardiorespiratory Fitness, and Clustered Cardiometabolic Risk in 10- to 12-year-old School Children: The REACH Y6 Study. Am. J. Hum. Biol. 2014, 26, 446-451. [CrossRef] [PubMed] 
7. Owen, C.G.; Nightingale, C.M.; Rudnicka, A.R.; van Sluijs, E.M.F.; Ekelund, U.; Cook, D.G.; Whincup, P.H. Travel to School and Physical Activity Levels in 9-10 Year-Old UK Children of Different Ethnic Origin; Child Heart and Health Study in England (CHASE). PLoS ONE 2012, 7, e30932. [CrossRef] [PubMed]

8. Roth, M.A.; Millett, C.J.; Mindell, J.S. The contribution of active travel (walking and cycling) in children to overall physical activity levels: A national cross sectional study. Prev. Med. 2012, 54, 134-139. [CrossRef] [PubMed]

9. Department for Transport. National Travel Survey: England 2015. Statistical Release-National Travel Survey; Department for Transport: London, UK, 2016.

10. Page, A.S.; Cooper, A.R.; Griew, P.; Jago, R. Independent mobility, perceptions of the built environment and children's participation in play, active travel and structured exercise and sport: The PEACH Project. Int. J. Behav. Nutr. Phys. Act. 2010, 7, 17. [CrossRef] [PubMed]

11. Panter, J.R.; Jones, A.P.; Van Sluijs, E.M.; Griffin, S.J. Neighborhood, route, and school environments and children's active commuting. Am. J. Prev. Med. 2010, 38, 268-278. [CrossRef] [PubMed]

12. Titheridge, H.; Christie, N.; Mackett, R.; Hernández, D.O.; Ye, R. Transport and Poverty: A Review of the Evidence; UCL Transport Institute, University College London: London, UK, 2014.

13. HM Government. Childhood Obesity: A Plan for Action; HM Government: London, UK, 2016.

14. Larouche, R.; Saunders, T.J.; Faulkner, G.E.J.; Colley, R.; Tremblay, M. Associations between Active School Transport and Physical Activity, Body Composition, and Cardiovascular Fitness: A Systematic Review of 68 Studies. J. Phys. Act. Health 2014, 11, 206-227. [CrossRef] [PubMed]

15. Ostergaard, L.; Kolle, E.; Steene-Johannessen, J.; Anderssen, S.A.; Andersen, L.B. Cross sectional analysis of the association between mode of school transportation and physical fitness in children and adolescents. Int. J. Behav. Nutr. Phys. Act. 2013, 10, 91. [CrossRef] [PubMed]

16. Voss, C.; Sandercock, G. Aerobic Fitness and Mode of Travel to School in English Schoolchildren. Med. Sci. Sports Exerc. 2010, 42, 281-287. [CrossRef] [PubMed]

17. Chaufan, C.; Yeh, J.; Ross, L.; Fox, P. Exploring the associations between active school transport, child obesity, and child poverty in California. J. Behav. Health 2012, 1, 35-41. [CrossRef]

18. Heelan, K.A.; Donnelly, J.E.; Jacobsen, D.J.; Mayo, M.S.; Washburn, R.; Greene, L. Active Commuting to and from School and BMI in Elementary School Children-Preliminary Data. Child Care Health Dev. 2005, 31, 341-349. [CrossRef] [PubMed]

19. Sarmiento, O.L.; Lemoine, P.; Gonzalez, S.A.; Broyles, S.T.; Denstel, K.D.; Larouche, R.; Onywera, V.; Barreira, T.V.; Chaput, J.P.; Fogelholm, M.; et al. Relationships between active school transport and adiposity indicators in school-age children from low-, middle- and high-income countries. Int. J. Obes. Suppl. 2015, 5 , S107-S114. [CrossRef] [PubMed]

20. Gutiérrez-Zornoza, M.; Sánchez-López, M.; García-Hermoso, A.; González-García, A.; Chillón, P.; Martínez-Vizcaíno, V. Active Commuting to School, Weight Status, and Cardiometabolic Risk in Children From Rural Areas: The Cuenca Study. Health Educ. Behav. 2015, 42, 231-239. [CrossRef] [PubMed]

21. Villa-González, E.; Ruiz, J.R.; Chillón, P. Associations between Active Commuting to School and Health-Related Physical Fitness in Spanish School-Aged Children: A Cross-Sectional Study. Int. J. Environ. Res. Public Health 2015, 12, 10362-10373. [CrossRef] [PubMed]

22. Chillón, P.; Ortega, F.B.; Ruiz, J.R.; Veidebaum, T.; Oja, L.; Mäestu, J.; Sjöström, M. Active commuting to school in children and adolescents: An opportunity to increase physical activity and fitness. Scand. J. Public Health 2010, 38, 873-879. [CrossRef] [PubMed]

23. Ramírez-Vélez, R.; García-Hermoso, A.; Agostinis-Sobrinho, C.; Mota, J.; Santos, R.; Correa-Bautista, J.E.; Amaya-Tambo, D.C.; Villa-González, E. Cycling to School and Body Composition, Physical Fitness, and Metabolic Syndrome in Children and Adolescents. J. Pediatr. 2017, 188, 57-63. [CrossRef] [PubMed]

24. D’Haese, S.; De Meester, F.; De Bourdeaudhuij, I.; Deforche, B.; Cardon, G. Criterion distances and environmental correlates of active commuting to school in children. Int. J. Behav. Nutr. Phys. Act. 2011, 8, 88. [CrossRef] [PubMed]

25. Duncan, S.; White, K.; Mavoa, S.; Stewart, T.; Hinckson, E.; Schofield, G. Active Transport, Physical Activity, and Distance Between Home and School in Children and Adolescents. J. Phys. Act. Health 2016, 13, 447-453. [CrossRef] [PubMed]

26. McDonald, N.C. Children's mode choice for the school trip: The role of distance and school location in walking to school. Transportation 2008, 35, 23-35. [CrossRef] 
27. Lee, C.; Zhu, X.; Yoon, J.; Varni, J.W. Beyond Distance: Children's School Travel Mode Choice. Ann. Behav. Med. 2013, 45, 55-67. [CrossRef] [PubMed]

28. Zhu, X.; Lee, C. Correlates of walking to school and implications for public policies: Survey results from parents of elementary school children in Austin, Texas. J. Public Health Policy 2009, 30, S177-S202. [CrossRef] [PubMed]

29. Giles-Corti, B.; Wood, G.; Pikora, T.; Learnihan, V.; Bulsara, M.; Van Niel, K.; Timperio, A.; McCormack, G.; Villanueva, K. School site and the potential to walk to school: The impact of street connectivity and traffic exposure in school neighborhoods. Health Place 2011, 17, 545-550. [CrossRef] [PubMed]

30. Mitra, R.; Buliung, R.N. Built environment correlates of active school transportation: Neighborhood and the modifiable areal unit problem. J. Transp. Geogr. 2012, 20, 51-61. [CrossRef]

31. Hume, C.; Timperio, A.; Salmon, J.; Carver, A.; Giles-Corti, B.; Crawford, D. Walking and cycling to school: Predictors of increases among children and adolescents. Am. J. Prev. Med. 2009, 36, 195-200. [CrossRef] [PubMed]

32. Rosenberg, D.; Ding, D.; Sallis, J.F.; Kerr, J.; Norman, G.J.; Durant, N.; Harris, S.K.; Saelens, B.E. Neighborhood environment walkability scale for youth (NEWS-Y): Reliability and relationship with physical activity. Prev. Med. 2009, 49, 213-218. [CrossRef] [PubMed]

33. Kneeshaw-Price, S.; Saelens, B.; Sallis, J.; Glanz, K.; Frank, L.; Kerr, J.; Hannon, P.A.; Grembowski, D.E.; Chan, K.C.G.; Cain, K. Children's Objective Physical Activity by Location: Why the Neighborhood Matters. Pediatr. Exerc. Sci. 2013, 25, 468-486. [CrossRef] [PubMed]

34. Noonan, R.J.; Boddy, L.M.; Knowles, Z.R.; Fairclough, S.J. Cross-sectional associations between high-deprivation home and neighborhood environments, and health-related variables among Liverpool children. BMJ Open 2016, 6, e008693. [CrossRef] [PubMed]

35. Department for Communities and Local Government. The English Indices of Deprivation 2015; Communities and Local Government Publications: Wetherby, UK, 2015.

36. Public Health England. Liverpool Health Profile 2014; Public Health England: London, UK, 2014.

37. Cole, T.J.; Freeman, J.V.; Preece, M.A. Body mass index reference curves for the UK, 1990. Arch. Dis. Child. 1995, 73, 25-29. [CrossRef] [PubMed]

38. Cole, T.J.; Bellizzi, M.C.; Flegal, K.M.; Dietz, W.H. Establishing a standard definition for child overweight and obesity worldwide: International survey. BMJ 2000, 320, 1240-1243. [CrossRef] [PubMed]

39. Mirwald, R.L.; Baxter-Jones, A.D.G.; Bailey, D.A.; Beunen, G.P. An assessment of maturity from anthropometric measurements. Med. Sci. Sports Exerc. 2002, 34, 689-694. [PubMed]

40. Leger, L.A.; Mercier, D.; Gadoury, C.; Lambert, J. The multistage $20 \mathrm{~m}$ shuttle run test for aerobic fitness. J. Sports Sci. 1988, 6, 93-101. [CrossRef] [PubMed]

41. Boddy, L.M.; Thomas, N.E.; Fairclough, S.J.; Tolfrey, K.; Brophy, S.; Rees, A.; Knox, G.; Baker, J.S.; Stratton, S. ROC Generated Thresholds for Field-Assessed Aerobic Fitness Related to Body Size and Cardiometabolic Risk in Schoolchildren. PLoS ONE 2012, 7, e45755. [CrossRef] [PubMed]

42. Van Dyck, D.; De Bourdeaudhuij, I.; Cardon, G.; Deforche, B. Criterion distances and correlates of active transportation to school in Belgian older adolescents. Int. J. Behav. Nutr. Phys. Act. 2010, 7, 87. [CrossRef] [PubMed]

43. MIMAS. Available online: http://geoconvert.mimas.ac.uk/ (accessed on 25 June 2017).

44. McDonald, N.C. Critical Factors for Active Transportation to School among Low-Income and Minority Students: Evidence from the 2001 National Household Travel Survey. Am. J. Prev. Med. 2008, 34, 341-344. [CrossRef] [PubMed]

45. Pabayo, R.; Gauvin, L. Proportion of students who use various modes of transportation to and from school in a representative population-based sample of children and adolescents, 1999. Prev. Med. 2008, 46, 63-66. [CrossRef] [PubMed]

46. Conrad, D.; Capewell, S. Associations between deprivation and rates of childhood overweight and obesity in England, 2007-2010: An ecological study. BMJ Open 2012, 2, e000463. [CrossRef] [PubMed]

47. Nau, C.; Schwartz, B.S.; Bandeen-Roche, K.; Liu, A.; Pollak, J.; Hirsch, A.; Bailey-Davis, L.; Glass, T.A. Community Socioeconomic Deprivation and Obesity Trajectories in Children Using Electronic Health Records. Obesity 2015, 23, 207-212. [CrossRef] [PubMed] 
48. Nevill, A.M.; Duncan, M.J.; Lahart, I.; Sandercock, G. Modelling the association between weight status and social deprivation in English school children: Can physical activity and fitness affect the relationship? Ann. Hum. Biol. 2015, 43, 497-504. [CrossRef] [PubMed]

49. Stamatakis, E.; Wardle, J.; Cole, T.J. Childhood obesity and overweight trends in England: Evidence for growing socioeconomic disparities. Int. J. Obes. 2009, 34, 41-47. [CrossRef] [PubMed]

50. Ranjit, N.; Wilkinson, A.V.; Lytle, L.M.; Evans, A.E.; Saxton, D.; Hoelscher, D.M. Socioeconomic inequalities in children's diet: The role of the home food environment. Int. J. Behav. Nutr. Phys. Act. 2015, 12, S4. [CrossRef] [PubMed]

51. Cetateanu, A.; Jones, A. Understanding the relationship between food environments, deprivation and childhood overweight and obesity: Evidence from a cross sectional England-wide study. Health Place 2014, 27, 68-76. [CrossRef] [PubMed]

52. Patterson, R.; Risby, A.; Chan, M.Y. Consumption of takeaway and fast food in a deprived inner London Borough: Are they associated with childhood obesity? BMJ Open 2012, 2, e000402. [CrossRef] [PubMed]

53. Braithwaite, I.; Stewart, A.W.; Hancox, RJ.; Beasley, R.; Murphy, R.; Mitchell, E.A.; The ISAAC Phase Three Study Group. Fast-food consumption and body mass index in children and adolescents: An international cross-sectional study. BMJ Open 2014, 4, e005813. [CrossRef] [PubMed]

54. Huang, J.Y.; Qi, S.J. Childhood obesity and food intake. World J. Pediatr. 2015, 11, 101-107. [CrossRef] [PubMed]

55. Lieberman, L.; Golden, S.D.; Earp, J.A.L. Structural Approaches to Health Promotion: What Do We Need to Know About Policy and Environmental Change? Health Educ. Behav. 2013, 40, 520-525. [CrossRef] [PubMed]

56. Sallis, J.F.; Cervero, R.B.; Ascher, W.; Henderson, K.A.; Kraft, M.K.; Kerr, J. An ecological approach to creating active living communities. Annu. Rev. Public Health 2006, 27, 297-322. [CrossRef] [PubMed]

57. Cooper, A.R.; Wedderkopp, N.; Wang, H.; Andersen, L.B.; Froberg, K.; Page, A.S. Active travel to school and cardiovascular fitness in Danish children and adolescents. Med. Sci. Sports Exerc. 2006, 38, 1724-1731. [CrossRef] [PubMed]

58. Ridley, K.; Ainsworth, B.; Olds, T. Development of a Compendium of Energy Expenditures for Youth. Int. J. Behav. Nutr. Phys. Act. 2008, 5, 45. [CrossRef] [PubMed]

59. Parikh, T.; Stratton, G. Influence of intensity of physical activity on adiposity and cardiorespiratory fitness in 5-18 year olds. Sports Med. 2011, 41, 477-488. [CrossRef] [PubMed]

60. Chillón, P.; Panter, J.; Corder, K.; Jones, A.P.; Van Sluijs, E.M.F. A longitudinal study of the distance that young people walk to school. Health Place 2015, 31, 133-137. [CrossRef] [PubMed]

61. Kerr, J.; Rosenberg, D.; Sallis, J.F.; Saelens, B.E.; Frank, L.D.; Conway, T.L. Active commuting to school: Associations with environment and parental concerns. Med. Sci. Sports Exerc. 2006, 38, 787-794. [CrossRef] [PubMed]

62. Voorhees, C.C.; Ashwood, S.; Evenson, K.R.; Sirard, J.R.; Rung, A.L.; Dowda, M.; McKenzie, T.L. Neighborhood design and perceptions: Relationship with active commuting. Med. Sci. Sports Exerc. 2010, 42, 1253-1260. [CrossRef] [PubMed]

63. DeWeese, R.S.; Yedidia, M.J.; Tulloch, D.L.; Ohri-Vachaspati, P. Neighborhood Perceptions and Active School Commuting in Low-Income Cities. Am. J. Prev. Med. 2013, 45, 393-400. [CrossRef] [PubMed]

64. Lansley, G. Cars and socio-economics: Understanding neighborhood variations in car characteristics from administrative data. Reg. Stud. Reg. Sci. 2016, 3, 264-285. [CrossRef]

65. Oliver, M.; Mavoa, S.; Badland, H.; Parker, K.; Donovan, P.; Kearns, R.A.; Lin, E.Y.; Witten, K. Associations between the neighborhood built environment and out of school physical activity and active travel: An examination from the Kids in the City study. Health Place 2015, 36, 57-64. [CrossRef] [PubMed]

66. Tasic, I.; Zlatkovic, M.; Martin, P.T.; Porter, R.J. Street Connectivity vs. Street Widening: Impact of Enhanced Street Connectivity on Traffic Operations in Transit Supportive Environments. Transp. Res. Rec. 2015. [CrossRef]

67. Leslie, E.; Cerin, E. Are perceptions of the local environment related to neighborhood satisfaction and mental health in adults? Prev. Med. 2008, 47, 273-278. [CrossRef] [PubMed]

68. Larsen, K.; Gilliland, J.; Hess, P.; Tucker, P.; Irwin, J.; He, M. The influence of the physical environment and sociodemographic characteristics on children's mode of travel to and from school. Am. J. Public Health 2009, 99, 520-526. [CrossRef] [PubMed] 
69. Ewing, R.; Schroeer, W.; Greene, W. School location and student travel: Analysis of factors affecting mode choice. Transport. Res. Rec. 2004, 1895, 55-63. [CrossRef]

70. Bostock, L. Pathways of disadvantage? Walking as a mode of transport among low-income mothers. Health Soc. Care Community 2001, 9, 11-18. [PubMed]

71. De Nazelle, A.; Nieuwenhuijsen, M.J.; Antó, J.M.; Brauer, M.; Briggs, D.; Braun-Fahrlander, C.; Cavill, N.; Cooper, A.R.; Desqueyroux, H.; Fruin, S.; et al. Improving health through policies that promote active travel: A review of evidence to support integrated health impact assessment. Environ. Int. 2011, 37, 766-777. [CrossRef] [PubMed]

72. Noonan, R.J.; Fairclough, S.J.; Knowles, Z.R.; Boddy, L.M. One Size Does Not Fit All: Contextualising Family Physical Activity Using a Write, Draw, Show and Tell Approach. Children 2017, 4, 59. [CrossRef] [PubMed]

(C) 2017 by the authors. Licensee MDPI, Basel, Switzerland. This article is an open access article distributed under the terms and conditions of the Creative Commons Attribution (CC BY) license (http:/ / creativecommons.org/licenses/by/4.0/). 